\title{
Young women's continued use of oral contraceptives over other hormonal methods: findings from a qualitative study
}

\author{
Lisa M Williamson, Katie Buston, Helen Sweeting
}

\begin{abstract}
Background Long-acting reversible contraceptives (LARC) have become more commonly promoted in the UK, but most young women still rely on the contraceptive pill. Here, we describe young women's accounts of hormonal contraceptive use to explore why this might be the case.
\end{abstract}

Methods In-depth interviews with twenty 20-year-old women from eastern Scotland in the UK.

Results All but one woman reported use of the pill. It was the method they expected to use, sought out, and received. Belief in the pill's efficacy was maintained even when knowledge or experience of failure suggested otherwise. Only four women reported using alternative hormonal methods and only did so after experiencing unmanageable problems with the pill (side effects or forgetting to take it). All then discontinued use because of weight gain or dislike of menstrual suppression.

Conclusions Attempts to promote LARC must address these issues. Pill use can be unproblematic if managed well, and should continue to be promoted as an appropriate contraceptive for young women.

Keywords contraceptive injection, hormonal contraception, long-acting reversible contraceptives, oral contraceptives, young women

J Fam Plann Reprod Health Care 2009; 35(3): 167-172

(Accepted 6 March 2009)

\section{Introduction}

In the UK, levels of reported contraceptive use are high (63\% of 16-19-year-olds and $84 \%$ of 20-24-year-olds report current use ${ }^{1}$ ), but so are unintended pregnancy rates. Recent research has estimated that nine-tenths of pregnancies among women requesting abortion are unintended, 2,3 while one in ten women who plan to continue their pregnancies suggest these were unintended and a further quarter report some ambivalence. ${ }^{2}$ In 2005 , the National Institute for Health and Clinical Excellence (NICE) advocated greater promotion of long-acting reversible (hormonal) contraceptives (LARC) to reduce unintended pregnancies. ${ }^{4}$ However, most young women still rely on the pill (here, 'the pill' refers to the combined oral contraceptive pill, unless otherwise stated) as their main method of contraception (other than condoms). In the 2006/07 Office for National Statistics Omnibus Survey, $64 \%$ of 20-24-year-old women reported pill use, but only $19 \%$ reported LARC use [injection, implant and intrauterine devices/intrauterine system (IUD/IUS)]. ${ }^{1}$

In this article we explore young women's use of hormonal contraceptives: the oral contraceptive pill and two alternatives - the injection and the progestogen-only pill (POP) - and discuss why it might be that the (combined) pill remains the dominant (hormonal) contraceptive method.

\section{Methods}

Findings in this article are from a qualitative study of young women's patterns of contraceptive use. ${ }^{5}$ Participants were selected from the sample of a randomised trial of a school-based sex education intervention (SHARE), ${ }^{6}$ and invited, by letter, to be interviewed at age 20 years. Semistructured interviews were conducted by the first author during the periods January-June 2003 and January-May

MRC Social and Public Health Sciences Unit, Glasgow, UK Lisa M Williamson, PhD, Research Scientist

Katie Buston, PhD, Research Scientist

Helen Sweeting, PhD, Research Scientist

Correspondence to: Dr Lisa Williamson, MRC Social and Public Health Sciences Unit, 4 Lilybank Gardens, Glasgow G12 8RZ, UK. E-mail: lisa@sphsu.mrc.ac.uk

\section{Key message points}

- In this qualitative study, use of hormonal contraceptives other than the pill was uncommon and only initiated after unmanageable problems with the pill were experienced.

- Pill use can be unproblematic if managed well and should continue to be promoted as an appropriate contraceptive for young women.

- The promotion of long-acting reversible contraceptives has to recognise the problems young women may encounter in initiating and adapting to such methods, particularly if weight gain/menstrual irregularity are experienced.

2004. The topic guide is shown in Table 1. Most of the interviews took place in the young women's own homes. The interviews were audio-recorded and averaged 1 hour in length. The young women were given pseudonyms.

Purposive sampling was used to select a heterogeneous group of young women with different levels of sexual experience and from different social backgrounds, based on area of residence, father's social class and own educational attainment (all associated with contraceptive use in quantitative analyses of the SHARE data). 5,7 Table 2 shows the basic demographic and sexual experience characteristics of the 20 interviewees, who were evenly split across the sampling frame groups. All but one was white, reflecting the relatively homogenous ethnic composition of the geographical area from which the sample was drawn.

The interviews were transcribed verbatim and analysed using Framework. ${ }^{8}$ This method allows for use of strategies similar to those employed in grounded theory, ${ }^{7,9}$ but within a more structured framework, which is systematic and replicable. Each transcript was reviewed for initial and emergent themes, which were then organised into topic areas to chart the data for thematic analysis. Using this approach allowed for themes to be compared across all interviews. The constant comparative method was used to examine similarities and differences between the interviews, and to understand and explain deviant cases in relation to the rest of the data. All authors read the interview transcripts in full and commented on the initial coding, emergent themes and analysis of the data. A detailed description of the study's methodology and data analysis is provided elsewhere. ${ }^{5}$ 
Table 1 Interview topic guidea

\section{General background}

- Ask to say a bit about self (i.e. family, friends, hobbies/going out/media etc)

\section{Current or most recent relationship}

- Background, how long, how met, etc?

- First sex

- Contraceptive use at first sex

- Influences - partner; other: family, friends, school, media

- Other contraceptive use in the relationship

- What use currently?

- Always used the method?

- Did you start using it with this partner?

- What other methods used with this partner?

- Influences - partner; other: family, friends, school, media

Personal use of contraceptives

- Experience of use - particular likes and dislikes, trust, pressure, regret of method use

- Access and use of services

- Benefits and risks of contraception

- Experience of pregnancy - ever worried about? And ever been? Personal and among friends/siblings, etc

- Emergency contraception use

\section{Future contraceptive use}

- Happy or not with current contraception? Why? (if not using any - how feel about it)

- Plan to change contraception in the future?

- What happens about contraceptive use if relationship comes to an end?
General knowledge of contraception

- Knowledge of different methods

- Access to methods

- How learned about these methods

Other relationships/sexual encounters

First sexual intercourse:

- Background

- Contraceptive use

- Partner? Background - as above

- Influences - partner; other: family, friends, school, media

Any other relationships/encounters:

- Background - as above

- Sex and contraceptive use

- What use currently?

- Always used the method?

- Did you start using it with this partner?

- What other methods used with this partner?

- Influences - partner; other: family, friends, school, media

Sexually transmitted infections

- Ever worried about infection? Why?

- Use of services - GUM/GP/other

- Experience of STIs

Importance of contraception

- Think about it often?

- Important to you?

- Major part of life or affects life in general?

aThe interviews were guided by the directions taken by the interviewees as they talked about their experiences. The guide was used as a checklist to ensure all topic areas were covered. A mixture of open-ended and semi-structured questions was used to illicit responses.

GP, general practitioner; GUM, genitourinary medicine; STI, sexually transmitted infection.

\section{Ethical approval}

Ethical approval for this study was granted by the Glasgow University Ethics Committee for Non-Clinical Research Involving Human Subjects.

\section{Results \\ Young women's use of hormonal contraceptives}

Table 3 shows the young women's reported use of hormonal contraceptive methods. All but one reported use of the pill. Half said they started the pill for a non-contraceptive reason, eight reported continuous use since starting it and six that they had started it in a relationship with a boyfriend and stopped when the relationship ended at some point in their sexual career. Only four young women reported using an alternative hormonal method (the injection and the POP). All changed method as a result of experiencing side effects or problems remembering to take the pill. All then discontinued use of the alternative method because of side effects (weight gain or not having a monthly period).

A number of themes were apparent in the young women's accounts of hormonal contraceptive method use (Table 4). To explore their evident reliance on the oral contraceptive pill these are discussed below under the following headings: (a) choosing a hormonal contraceptive method - expectations of use and the influence of others and (b) using a hormonal contraceptive method - efficacy and experience.

\section{Choosing a hormonal contraceptive method - expectations of use and the influence of others}

Most of the young women reported using condoms instead of hormonal contraceptives at sexual debut and the immediate period following this. All three women who had started the pill at this stage said it was for noncontraceptive reasons, and that they had used condoms when they first had sex. Only one conceded starting the pill was related to any expectation of having sex: “...it's [pill use] sorta the next big step in your life, you know? ... a decision that you're gonna have to make if you're going to start sleeping with people." [Melanie]

However, as they became more sexually experienced, most women described seeking to change to another method because of negative experiences of condom use (14 reported pill use at their most recent sexual experience). There appeared to be an expectation that this method should be the pill; it was "just what you did" to avoid pregnancy. Some also talked of how they thought their partners expected them to be on the pill:

"I think guys expect all women to be on the pill these days. ... Cos otherwise they wouldn't be saying it all the time, 'oh, are you on the pill?'.' [Lucy]

Conversely, none of the young women expressed any expectation of using an alternative LARC method. This did not appear to be because they were entirely unaware of these. When asked to name the contraceptive methods they had heard of, the injection and the intrauterine device (IUD) were named by 16 and 17 young women, respectively; only six named the implant. However, some appeared opposed to trying such methods:

"I don't think I would ever go on the jag [contraceptive injection], one of my friends did and she put on a lot of weight ..." [Milly]

Friends' negative experiences of these methods were commonly reported and some of the young women's partners also expressed concerns:

"And then I discussed [the injection] with [boyfriend] but he was like 'no, because the jag can make you infertile, and then when you come off you've got to wait like a year before you can have kids'., [Kim]

Friends' negative experiences of the pill were also 
Table 2 Basic demographic and sexual experience characteristics of the interviewees $(n=20)$

\begin{tabular}{|c|c|}
\hline Characteristic & Interviewees $(n)$ \\
\hline \multicolumn{2}{|l|}{ Sampling frame characteristics ${ }^{a}$} \\
\hline \multicolumn{2}{|l|}{ Sexual experience } \\
\hline $\begin{array}{l}\text { Two or more sexual partners by age } \\
16 \text { years }\end{array}$ & 6 \\
\hline $\begin{array}{l}\text { First sexual experience by age } \\
16 \text { years (one partner) }\end{array}$ & 7 \\
\hline $\begin{array}{l}\text { First sexual experience between age } \\
16 \text { and } 18 \text { years }\end{array}$ & 7 \\
\hline \multicolumn{2}{|l|}{ Father's social class } \\
\hline Manual & 10 \\
\hline Non-manual & 10 \\
\hline \multicolumn{2}{|l|}{ Educational attainment (at age 16 years) } \\
\hline Credit Standard Grades ${ }^{\mathrm{b}}$ & 10 \\
\hline General/foundation Standard Grades & 10 \\
\hline \multicolumn{2}{|l|}{ Area of residence } \\
\hline Main city & 9 \\
\hline Rest of study area & 11 \\
\hline \multicolumn{2}{|l|}{ Other demographic characteristicsc } \\
\hline \multicolumn{2}{|l|}{ Living arrangements } \\
\hline With parents & 12 \\
\hline With partner & 2 \\
\hline On own with (child/children) & 3 \\
\hline Student accommodation & 3 \\
\hline \multicolumn{2}{|l|}{ Current employment } \\
\hline Working full-time & 7 \\
\hline Working part-time & 4 \\
\hline Full-time mother & 2 \\
\hline In full-time education (college or university) & $\overline{7}$ \\
\hline \multicolumn{2}{|l|}{ Sexual experience ${ }^{c}$} \\
\hline Age at first sexual intercourse (range) & $12-17$ \\
\hline Total number of sexual partners (range) & $1-16$ \\
\hline Boyfriend relationships ${ }^{d}$ & 20 \\
\hline Casual sex partners ${ }^{d}$ & 16 \\
\hline $\begin{array}{l}\text { Coercive sexual experiences/abusive } \\
\text { relationships }\end{array}$ & 4 \\
\hline Pregnancy & 8 \\
\hline Tested for sexually transmitted infections & 9 \\
\hline Sexually transmitted infection & 1 \\
\hline \multicolumn{2}{|l|}{ Experience of contraceptive use (ever use)c } \\
\hline Condoms & 20 \\
\hline Pill & 19 \\
\hline Alternatives (e.g. injection) & 4 \\
\hline Emergency contraception & 16 \\
\hline Non-use (i.e. unprotected sex) & 10 \\
\hline
\end{tabular}

aAs reported in survey data at age 16 or 18 years.

bStandard Grades are the examinations at the end of statutory education, with credit being the highest level.

cAs reported at interview at age 20 years.

dBoyfriends were often simply described as such, but were distinguished from more casual sex partners by involving a longer-term relationship and involving an emotional attachment. Casual sex partners were casual acquaintances or men met in social venues with whom the young women had one-off sexual encounters.

reported but did not appear to have the same off-putting effect as their experiences of LARC. When a friend became pregnant while using the pill, it was often blamed on her incorrect or inconsistent use of the method rather than the method itself:

"I trust [the pill] because nothing's ever happened on it but one of the guys that I know, his wife got pregnant on the pill. But in all fairness, I don't think she was taking it because their marriage was on the rocks and I think she had the kid to kind of keep it all together." [Megan]

Although, in order to start the pill, the women described specifically seeking it out from a general practitioner (GP) or clinic, most young women said they were not offered an alternative. The pill (and often one particular brand) was what was offered, and what was expected:
"Cos I think they put everyone on the same one to start with unless you've got like a medical history or anything like that." [Kate]

Alternatives only appeared to be offered when problems were experienced with the pill:

"I went in and just spoke to the woman ... in the family planning clinic and she said that like that would probably be the best thing if I was forgetting it all the time, would be to take ... get the jag [injection] and then all you need to remember is your three month appointment." [Megan]

\section{Using a hormonal contraceptive method - efficacy and experience}

The young women's pill use appeared to make them feel safer, and gave them a greater sense of control over their pregnancy prevention than condoms:

"I like the fact that, you know ... is it 99 point something per cent effective, and the only way that it's gonnae ... its not like condoms which can burst of their own accord and stuff, the only way the pill's gonnae go wrong is if you muck it up yourself ..." [Kathy]

This appeared to have encouraged continued use, even in the light of negative experiences or knowledge of pill failures:

"Em ... nothing really changed after that [the pregnancy]. Just thought, you know, unlucky month [laughs]. Never thought like any less of ... coming off the pill or what have you. No, cos my mum fell pregnant wi me when she was on the pill, so I just thought 'och, it's just one of these things that happen'..." [Margaret]

However, the small number of young women who described experiencing side effects had to stop using the pill:

"I had tae actually get taken off the pill cos I was getting really really bad headaches. And they took me off the pill saying it could be that." [Fiona]

Yet, their belief in the pill was maintained. Indeed, when later wanting to change from the injection, one woman could not understand why another pill had not been offered to her in the first place:

"... [doctor] turned round and said 'the only other thing is the injection', whereas now the pill that I'm on, they could have put me on that straight from that one." [Margaret]

Continued pill use appeared to be further reinforced by the non-contraceptive benefit of menstrual regulation, which 14 women reported liking. The presence of the monthly withdrawal bleed was talked of as a way of checking you were not pregnant:

"I like the fact that it's peace of mind, you get your period at the end of every month, it's like the same time, so you know that you're not pregnant as well." [Milly]

In contrast, the absence of the monthly withdrawal bleed was talked about as a reason for discontinuing the POP:

"I think it was just the whole bit about no getting your periods I didnae like. It made you wonder 'has it worked?' and 'are you pregnant?' and kinda there was nae real point in it. You were still worrying every month when you never got your period." [Fiona]

Not all thought withdrawal bleed suppression was negative. One of the young women who had used the injection talked of it as one aspect of this method she liked. 


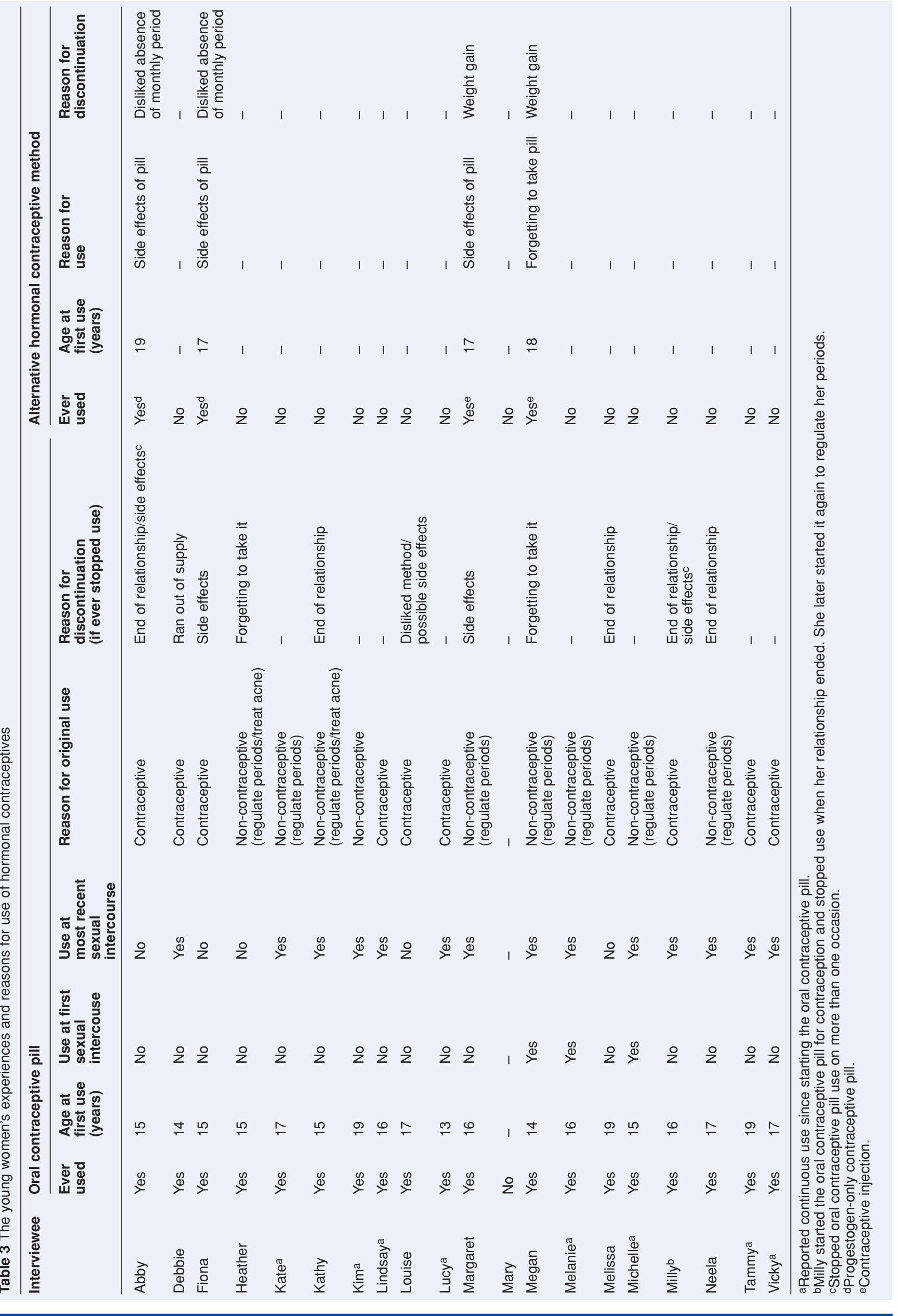


Table 4 Themes on use and discontinuation of hormonal contraceptive methods

\begin{tabular}{l} 
Oral contraceptive pill \\
\hline Push factors encouraging use \\
- Greater efficacy and safety \\
- Ex-contraceptive reasons \\
- Accessibility \\
Pull factors discouraging use \\
- Experience of side effects \\
- Norgetting to take/running out of the pill
\end{tabular}

Alternative hormonal contraceptive method

Push factors encouraging use

- Side effects/problems with the routine of the oral contraceptive pill

- Health care practitioner influence

Pull factors discouraging use

- Experience and dislike of side effects

- Negative experience of others

aBoyfriends were often simply described as such, but were distinguished from more casual sex partners by involving a longer-term relationship and involving an emotional attachment.

Even so, she then said that she had discontinued use because of weight gain:

“... I'd put on a lot of weight while I'd been on the injection. ... it was quite scary how much weight I'd put on ... put on about two stone." [Megan]

Both women who used the injection said that they had gained substantial weight while using it and this was their reason for discontinuing use (which parallels the reason for non-use provided by those who had not tried the method).

Finally, pill discontinuation also appeared to be related to problems with the routine of use. Half the women said that they frequently forgot to take the pill, but only five reported stopping use as a result (four of whom described starting it again at a later date). Those who struggled most with the routine of the pill and stopped taking it reported doing so because they were not in a relationship at the time:

“... see like when you're on the pill and you're seeing your boyfriend every day, it's like you remember to take it for some reason but if you've no got any guy that's on your heid or that, it just ... it just went right out of ma heid, eh?" [Melissa]

For the most part, the young women said that they would struggle on with taking the pill. Some described asking friends or boyfriends to remind them or, as two reported, using mobile phone reminders:

"I sat and put ... all the reminders on my phone for like 5 to 8, so just before I left the house I knew if I hadn't taken it..." [Megan]

For the majority, pill use appeared to become a routine part of their lives, supporting their continued use, even outside relationships when they were not having sex. Using the pill was convenient, easy and became something done automatically:

"It's convenient and it takes what a second to pop it in your mouth, that's it so. It does me; it suits me and my lifestyle perfectly..." [Kim]

\section{Discussion}

Among the young women interviewed in this study, use of the contraceptive pill was more common and consistent than use of other hormonal contraceptives. However, there are some study limitations to consider.

The findings are from a small qualitative sample within one particular geographical locality (eastern Scotland) and caution should be taken generalising beyond this population. Due to the nature of the sampling frame, the sample may be over-representative of those at potentially greatest risk. Eleven $(55 \%)$ of the interviewees had first had sex by age 16 years, compared with $28 \%$ of $20-24-$ year-old females in the 2000 National Survey of Sexual Attitudes and Lifestyles, three (15\%) reported pill use at first sexual intercourse compared with $25 \%$, and three $(15 \%)$ reported motherhood before age 18 years compared with only $6 \% .{ }^{10}$ As so few of the women reported use of alternatives (particularly LARC), their experiences might not generalise to those of others. Furthermore, the interviews were conducted before the UK policy initiatives advocating greater promotion of LARC. It remains to be seen whether more young women will select, and report sustained use of, LARC as these are further promoted (and possibly accepted). However, few UK studies have examined women's experiences of LARC and most knowledge is based on literature from the USA, which may not be relevant to the UK context.

In our study, all but one of the young women said that they had used the pill, few reported discontinuing use once started, and only four said they had used an alternative hormonal method. Our finding that the use of such alternative methods was limited in the absence of side effects or unmanageable problems with pill use has important implications for contraceptive service provision. The following discussion concentrates on this (further contextualisation and discussion of all of the young women's hormonal contraceptive use is provided elsewhere). 5

Most of the young women reported using condoms during their early sexual experiences, but then described seeking an alternative as a result of negative experiences of condom use. ${ }^{11}$ Supporting findings from elsewhere, ${ }^{12}$ it was the contraceptive pill they said they expected to use, sought out, and received at this stage. The young women's negative experiences of the pill had little effect on them; neither did those of their friends. Their belief in the pill, even when it failed, seemed almost unshakable. This was the case among both those who had only used the pill and those who had tried alternative hormonal methods.

In contrast, friends' negative experiences of LARC were frequently cited as a reason not to try these. Other research has found it is difficult for women to select a method (such as the implant), which is less common or regarded as unusual. ${ }^{12,13}$ Although negative experiences of alternative methods are commonly shared, ${ }^{12,13}$ positive experiences are often withheld. ${ }^{13}$

It is particularly striking that none of the women reported sustained use of the injection or implant, even though many were aware of these methods. This corresponds with recent figures suggesting LARC use remains low among women aged less than 25 years. ${ }^{1}$ Furthermore, a recent survey of GPs in the UK also found the pill remained the main method they would prescribe for contraception; although $81 \%$ thought that LARC methods 
had an important role in teenage pregnancy prevention, just under half said they would not be their first prescription choice. ${ }^{14}$ It has also been suggested that GPs may not want to suggest an alternative when the pill is what is specifically asked for. ${ }^{12}$ Here, those who had sought out and used alternative methods only did so after experiencing unmanageable problems with the pill. In the absence of such problems, there was apparently no need to change to (or even request) an alternative method.

However, all four women who had used an alternative method said they then discontinued use of these because they disliked the side effects they attributed to it: weight gain for the injection and menstrual suppression for the POP. Although contested, ${ }^{15-17}$ weight gain is regularly reported as a side effect in studies of women's attitudes and experiences of the method, 18 and a recent study found that even providing accurate information was not totally successful in dispelling such negative attitudes. ${ }^{12}$ Qualitative studies of young women also continue to highlight concerns about menstrual irregularity, including suppression. ${ }^{19,20}$ Here, menstrual regulation was a popular non-contraceptive benefit of the pill, and the absence of the regular, monthly bleed was unacceptable. Although there may be no clinical need for the withdrawal bleed, 21 this is what young women are used to and they may rely on it regardless.

Our findings suggest that ingrained expectations of use (among women and their health care providers), peer support, and negative attitudes and experiences of LARC could explain why the pill remains the dominant hormonal contraceptive method among young women. However, our findings also suggest use of the pill can be unproblematic if managed well. It should continue to be promoted as an appropriate contraceptive method for young women, and perhaps accompanied by guidance on coping with the routine of use, including advocating the use of technologybased reminders (e.g. mobile phone alerts).22,23 Greater use of LARC has been advocated as a means of reducing unintended pregnancies, and could offer an alternative for women who struggle with the routine of the pill, but attempts to promote these methods have to recognise and address the problems that women may encounter in initiating and adapting to them. Otherwise the risk of discontinuation, and hence unintended pregnancy, will be high.

\section{Acknowledgement}

The authors want to thank the 20 young women who took part in the interviews.

\section{Statements on funding and competing interests}

Funding The study was funded by the UK Medical Research Council as part of the Sexual and Reproductive Health Programme (WBS U.1300.00.005) at the Social and Public Health Sciences Unit.

Competing interests None identified.

\section{References}

1 Lader D. Contraception and Sexual Health 2006/07. London, UK: Office for National Statistics, 2007.

2 Lakha F, Glasier A. Unintended pregnancy and use of emergency contraception among a large cohort of women attending for antenatal care or abortion in Scotland. Lancet 2006; 368: 1782-1787.

3 Schünmann C, Glasier A. Measuring pregnancy intention and its relationship with contraceptive use among women undergoing therapeutic abortion. Contraception 2006; 73: 520-524.

4 National Institute for Health and Clinical Excellence (NICE). Long-Acting Reversible Contraception (Clinical Guideline No. 30). London, UK: NICE, 2005

5 Williamson LM. Contraceptive careers: young women's choices, influences and risks. PhD thesis, University of Glasgow, Glasgow, UK, 2007. E-thesis available at http://theses.gla.ac.uk/164/ [Accessed 26 November 2008].

6 Wight D, Raab GM, Henderson M, Abraham C, Buston K, Hart $G$, et al. Limits of teacher delivered sex education: interim behavioural outcomes from randomised trial. BMJ 2002; 324: 1430 [erratum appears in BMJ 2002; 325: 435].

7 Silverman D. Doing Qualitative Research: A Practical Handbook (2nd edn). London, UK: SAGE, 2005.

8 Ritchie J, Spencer L. Qualitative data analysis for applied policy research. In: Bryman A, Burgess RG (eds). Analyzing Qualitative Data. London, UK: Routledge, 1994.

9 Glaser B, Strauss A. The Discovery of Grounded Theory. Chicago, IL: Aldine, 1967.

10 Wellings K, Nanchahal K, Macdowall W, McManus S, Erens B, Mercer $\mathrm{CH}$, et al. Sexual behaviour in Britain: early heterosexual experience. Lancet 2001; 358: 1843-1850.

11 Williamson LM, Buston K, Sweeting H. Young women and limits to the normalisation of condom use: a qualitative study. AIDS Care 2009; 21: 561-566.

12 Glasier A, Scorer J, Bigrigg A. Attitudes of women in Scotland to contraception: a qualitative study to explore acceptability of long-acting methods. J Fam Plann Reprod Health Care 2008; 34: 213-217.

13 Kuiper H, Miller S, Martinez E, Loeb L, Darney P. Urban adolescent females' views on the implant and contraceptive decision-making: a double paradox. Fam Plann Perspect 1997; 29: 167-172.

14 Wellings K, Zhihong Z, Krentel A, Barrett G, Glasier A. Attitudes towards long-acting reversible methods of contraception in general practice in the UK. Contraception 2007; 76: 208-214.

15 Bonny AE, Ziegler J, Harvey R, Debanne SM, Secic M, Cromer BA. Weight gain in obese and nonobese adolescent girls initiating depot medroxyprogesterone, oral contraceptive pills, or no hormonal contraceptive method. Arch Pediatr Adolesc Med 2006; 160: 40-45.

16 Risser WL, Gefter LR, Barratt MS, Risser JMH. Weight change in adolescents who used hormonal contraception. $J$ Adolesc Health 1999; 24: 433-436.

17 Pelkman C. Hormones and weight change. J Reprod Med 2002; 47: 791-794.

18 Brown KE, Arden MA, Hurst KM. A qualitative analysis of accounts of hormonal contraceptive use: experiences and beliefs of British adolescents. Eur J Contracept Reprod Health Care 2007; 12: 269-278.

19 Cheung E, Free C. Factors influencing young women's decision making regarding hormonal contraceptives: a qualitative study. Contraception 2005; 71: 426-431.

20 Clark LR, Barnes-Harper KT, Ginsburg KR, Holmes WC Schwarz DF. Menstrual irregularity from hormonal contraception: a cause of reproductive health concerns in minority adolescent young women. Contraception 2006; 74: 214-219.

21 Archer DF. Menstrual-cycle-related symptoms: a review of the rationale for continuous use of oral contraceptives. Contraception 2006; 74: 359-366.

22 Lachowsky M, Levy-Toledamo R. Improving compliance in oral contraception: 'the reminder card'. Eur J Contracept Reprod Health Care 2002; 7: 210-215.

23 Fox MC, Creinin MD, Murthy AS, Harwood B, Reid LM. Feasibility study of the use of a daily electronic mail reminder to improve oral contraceptive compliance. Contraception 2003; 68: $365-371$.

\section{READERS' CONTRIBUTIONS INVITED ON 'A BETTER WAY OF WORKING'}

Continuing in this issue (see article on page 203) is the feature entitled 'A Better Way of Working', the purpose of which is to disseminate service delivery suggestions likely to be of interest and relevance to the Journal's readership.

Readers are invited to submit suggestions based on their own personal experience for consideration by the Journal Editor. Contributions normally should not exceed 250-500 words and should be written in a standardised format responding to the following four questions (or similar): Why was change needed? How did you go about implementing change? What advice would you give to others who might be considering a similar course of action? How did you show that the change had occurred?

All contributions should be submitted via the Journal's online submission system at http://jfprhc.allentrack.net. 